\title{
Demand response: a strategy to address residential air-conditioning peak load in Australia
}

\author{
Robert SMITH ( $\square)$, Ke MENG, Zhaoyang DONG, \\ Robert SIMPSON
}

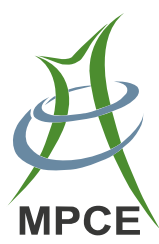

\begin{abstract}
Rapid growth in electricity network peak demand is increasing pressure for new investment which may be used for only a few hours a year. Residential airconditioning is widely believed to be the prime cause of the rise in peak demand but, in the absence of detailed residential demand research, there is no bottom-up empirical evidence to support this supposition or to estimate its impact. This paper first examines the developments in network peak demand, at a national, network distribution, and local distribution feeder level to show recent trends in peak demand. Secondly, this paper applies analytics to the half-hourly consumption data of a sample of Ausgrid's interval metered customers, combined with local weather data, to develop an algorithm which can recognize air-conditioner use and can identify consumption patterns and peak load. This estimate is then compared to system peaks to determine residential airconditioning's impact on overall demand. Finally, this paper considers the future impacts of air-conditioning load on peak demand as penetration rates reaches saturation levels and new minimum energy performance standards take effect reducing new units peak impacts.
\end{abstract}

Keywords Air conditioner, Demand response, Peak load

Received: 25 July 2013/Accepted: 21 October 2013/Published online: 26 November 2013

(C) The Author(s) 2013. This article is published with open access at Springerlink.com

R. SMITH, R. SIMPSON, Ausgrid, Sydney, NSW 2000,

Australia

( $₫)$ e-mail: rsmith@ ausgrid.com.au

R. SIMPSON

e-mail: robert.simpson@ausgrid.com.au

K. MENG, Z. DONG, Center for Intelligent Electricity Networks

(CIEN), The University of Newcastle, Newcastle, NSW,

Australia

K. MENG

e-mail: ke.meng@newcastle.edu.au

Z. DONG

e-mail: joe.dong@newcastle.edu.au

\section{Introduction}

Electricity peak demand is increasing rapidly in Australia in the past decade, driven by the connection of new businesses and homes, and also by a rise in the use of air conditioners. The residential air-conditioning load is widely believed to be a significant portion of electric utility peak load, which is a major driver of investment for electricity network and generating facilities. This rapid uptake has major ramifications for national electricity infrastructures and requires large investment to cope with short peaks in load. The federal government energy white paper [1] characterizes this problem as a customer' purchase of a $\$ 1,500$ air-conditioner driving $\$ 7,000$ of extra augmentation capital expenditure across the electricity grid. Therefore, if without detailed residential air-conditioning load research, there will be no bottom-up empirical evidence to estimate its impacts and to reduce growthrelated infrastructure investment.

Many Australian utilities have identified the enormous challenges of the increasing peak demand to the operation of future power grids [2]. They are devoting increasing resource to address the peak demand problems, and are promoting industry and academia to conduct joint research to improve transition of latest research results into industrial applications. Shaving or shifting the peak demand is one of the most direct ways to address the air-conditioning load issues. A lot of interests have been directed towards shifting peak load to off-peak periods. Four key initiatives are listed as follows [3].

1) Keep the customers updating with varying prices and let them decide when to modify or curtail their energy use;

2) Direct load control of major contributors of peak demand (air conditioning, pool pumps, water heaters, and etc); 
3) Small-scale distributed generations (solar, wind, electric vehicles, energy storage, and etc);

4) Improve energy efficiency standards (buildings thermal performance, electric appliance efficiency, and etc).

Large-scale deployment of these programs has the potential to reduce the need for expensive peak generations, to provide significant bill savings for customers, to enhance electric system reliability, and to increase the penetrations of intermittent renewable energy [4]. However, at the current stage, most of the activities and initiatives aiming at reducing peak load focused on the commercial and industrial sectors where are logistically easier to be implemented than in the residential sector [5]. But it is reported that the peak demand from residential air conditioners will grow more rapidly in the near future. Consequently, the key element for further development is to design a program which can help to address the peak demand of residential air-conditioning units directly. While progress has been made in recent years, more effort is needed in the future.

This paper is organized as follows - after introduction section, the developments in network peak demand, at a national, network distribution, and local distribution feeder level is examined to show recent trends in peak demand. After that, half-hourly metered customer load data from Ausgrid, combined with local weather data is used to develop an algorithm which can predict air-conditioner existence and identify consumption patterns and peak demand, followed by the determination of residential airconditioning's impacts on the whole power network. Finally, future impacts of air-conditioning load on peak demand as penetration rates reaches saturation levels are discussed and new minimum energy performance standards take effect reducing new units peak impacts are proposed. Conclusions and further developments are provided in the last section.

\section{Customer demand and temperature}

In this section, the developments in network peak demand are studied to show recent trends in peak load. Moreover, the load patterns and the temperature profiles are studied together so that the average phase relationship between the demand and the temperature in four seasons can be observed respectively.

\subsection{National demand}

Summary of national demand in different years is shown in Table 1.
Table 1 Summary of demand of Australian NEM (mw)

\begin{tabular}{lllll}
\hline Year & Maximum & Mean & Median & Minimum \\
\hline 2009 & $35,433.42$ & $23,408.38$ & $23,561.79$ & $15,881.00$ \\
2010 & $33,752.42$ & $23,329.49$ & $23,543.23$ & $15,455.58$ \\
2011 & $34,887.65$ & $22,924.67$ & $23,166.51$ & $15,144.41$ \\
\hline
\end{tabular}

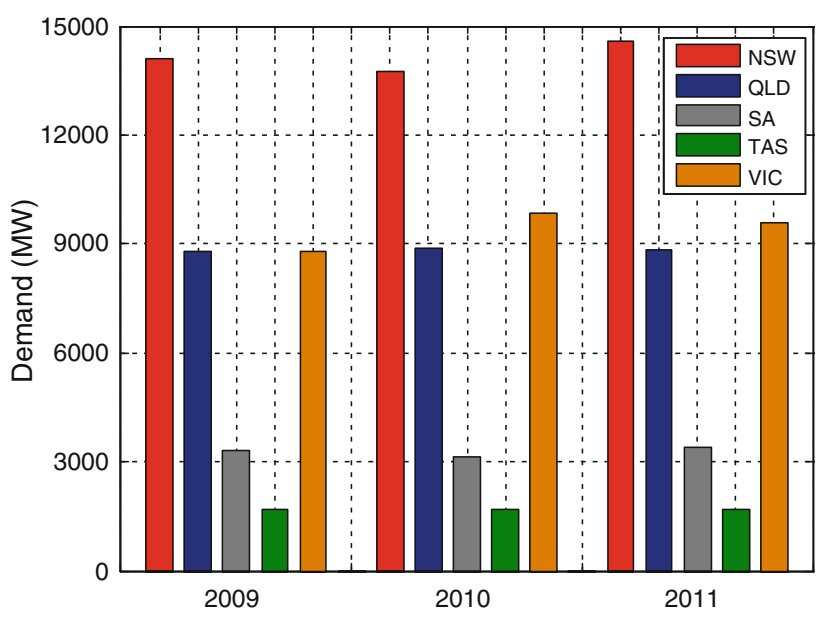

Fig. 1 Regional peak demand in Australian NEM

Regional peak demand in Australian national electricity market (NEM) is shown in Fig. 1. The Australian NEM is composed of the states of New South Wales (NSW), Queensland (QLD), South Australia (SA), Tasmania (TAS), and Victoria (VIC) [6]. The average electricity demand in the east Australian states of NSW, QLD, and VIC are much higher than that of the other two states. In the NEM, demand for electricity has been falling in recent years; however the rise in peak demand has been even more pronounced [7]. Our study shows that a significant portion of the reduction in electricity demand in the NEM is attributed to a shift away from grid-sourced electricity.

\subsection{Household demand}

In the past decade, residential load has undergone substantial changes with higher volatility and greater unpredictability. In the following study, the half-hourly end-user metered load data from 180 of Ausgrid's customers is analysed. The demand data covers one year, from 01 May 2010 to 30 April 2011. The comparisons of the half-hourly average customer household load of four seasons are shown in Fig. 2. The four seasons in Australia are winter (Jun.-Aug.), spring (Sep.-Nov.), summer (Dec.-Feb.), and autumn (Mar.-May).

The figures above illustrate the different level of averaged customer load of four different seasons. It is easy to find the household demand in winter is higher than in the 


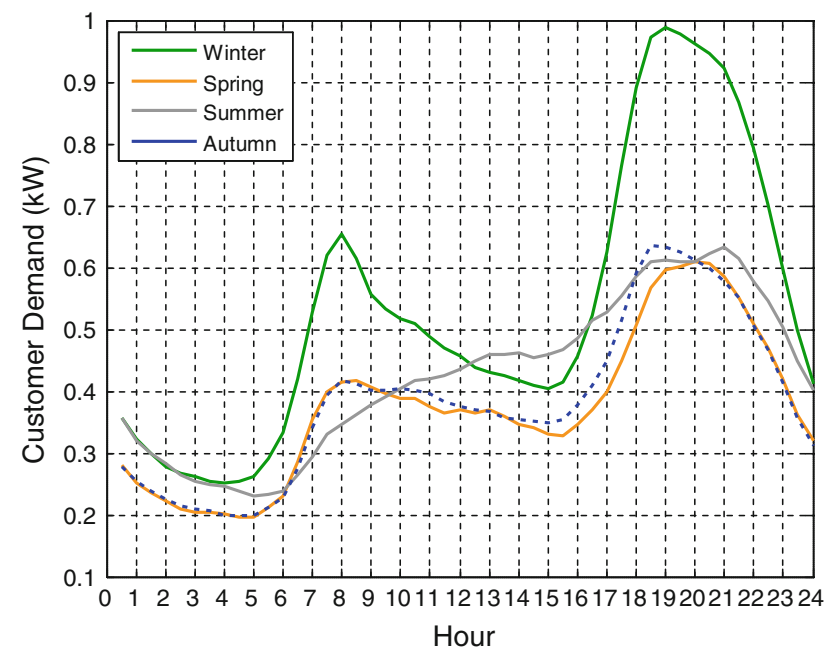

Fig. 2 Half-hourly average customer household load of different seasons

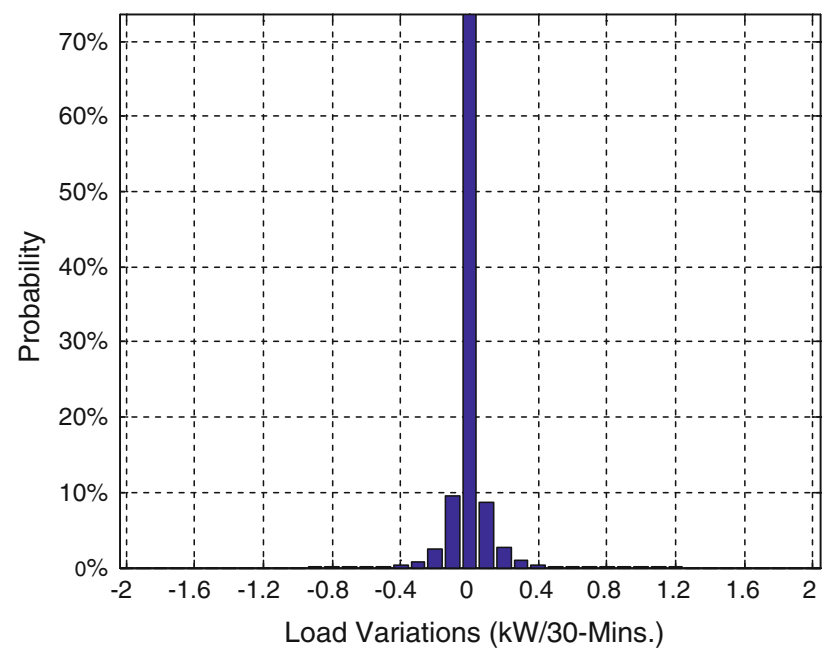

Fig. 3 Distribution of load variations of one customer

other seasons during the studied period. It is noticeable that the daily demand in winter is between 0.2 and $1.0 \mathrm{~kW}$, with two peaks in the morning and in the evening, respectively. The lowest point is at around 04:00 in the early morning. On the contrary, in summer, the daily load curve is relatively flat, which climbs from early morning to late evening gradually, and then drops rapidly to the morning level again. The demand in spring and autumn show basically the same patterns as it is in winter, but only in much lower levels. Generally, in Australia, the equipments that drive summer peak demand include air conditioners, pool pumps, and etc. In winter, electricity needed to operate heating systems significantly contributes to the peak demand. The basic load is driven by devices that are used year-round, like fridges, electric water heaters, dishwashers, clothes washers and dryers, hot tubs and waterbed
Table 2 Statistics of customer load variations $(\mathrm{kW})$

\begin{tabular}{|c|c|c|c|c|}
\hline $\begin{array}{l}\text { Customer } \\
\text { ID }\end{array}$ & Mean & Std. & Max. J.U. & $\begin{array}{l}\text { Max. } \\
\text { J.D. }\end{array}$ \\
\hline 1 & $-6.56 \mathrm{E}-06$ & $9.48 \mathrm{E}-02$ & 1.236 & 0.935 \\
\hline 2 & $4.28 \mathrm{E}-06$ & $2.42 \mathrm{E}-01$ & 2.637 & 2.055 \\
\hline 3 & $1.06 \mathrm{E}-05$ & $2.64 \mathrm{E}-01$ & 2.511 & 2.130 \\
\hline 4 & $-1.71 \mathrm{E}-07$ & $2.14 \mathrm{E}-01$ & 1.796 & 1.402 \\
\hline 5 & $1.82 \mathrm{E}-05$ & $2.09 \mathrm{E}-01$ & 2.379 & 1.745 \\
\hline 6 & $-1.20 \mathrm{E}-05$ & $1.31 \mathrm{E}-01$ & 1.465 & 1.144 \\
\hline 7 & $-9.93 \mathrm{E}-06$ & $1.55 \mathrm{E}-01$ & 1.719 & 1.653 \\
\hline 8 & $-2.11 \mathrm{E}-06$ & $4.77 \mathrm{E}-01$ & 4.095 & 3.422 \\
\hline 9 & $2.28 \mathrm{E}-07$ & $2.61 \mathrm{E}-01$ & 1.523 & 1.768 \\
\hline 10 & $-1.25 \mathrm{E}-05$ & $1.62 \mathrm{E}-01$ & 2.077 & 2.008 \\
\hline 11 & $-3.03 \mathrm{E}-06$ & $3.40 \mathrm{E}-01$ & 3.960 & 3.662 \\
\hline 12 & $7.64 \mathrm{E}-05$ & $2.88 \mathrm{E}-01$ & 2.416 & 2.083 \\
\hline 13 & $5.71 \mathrm{E}-08$ & $1.02 \mathrm{E}-01$ & 2.294 & 1.559 \\
\hline 14 & $6.28 \mathrm{E}-07$ & $2.28 \mathrm{E}-01$ & 1.864 & 1.510 \\
\hline 15 & $1.37 \mathrm{E}-06$ & $1.26 \mathrm{E}-01$ & 1.365 & 1.290 \\
\hline 16 & $2.45 \mathrm{E}-06$ & $2.03 \mathrm{E}-01$ & 1.765 & 1.962 \\
\hline 17 & $-8.56 \mathrm{E}-07$ & $2.77 \mathrm{E}-01$ & 2.350 & 2.085 \\
\hline 18 & $4.77 \mathrm{E}-05$ & $2.89 \mathrm{E}-01$ & 2.615 & 2.064 \\
\hline 19 & $1.49 \mathrm{E}-05$ & $4.13 \mathrm{E}-01$ & 4.592 & 4.328 \\
\hline 20 & $2.28 \mathrm{E}-06$ & $1.97 \mathrm{E}-01$ & 2.008 & 2.515 \\
\hline 21 & $-5.71 \mathrm{E}-07$ & $1.58 \mathrm{E}-01$ & 2.054 & 1.721 \\
\hline 22 & $-6.28 \mathrm{E}-06$ & $1.37 \mathrm{E}-01$ & 1.338 & 1.323 \\
\hline 23 & $-7.47 \mathrm{E}-05$ & $4.76 \mathrm{E}-01$ & 3.715 & 3.130 \\
\hline 24 & $-6.85 \mathrm{E}-06$ & $2.17 \mathrm{E}-01$ & 2.417 & 1.712 \\
\hline 25 & $3.11 \mathrm{E}-05$ & $6.13 \mathrm{E}-01$ & 6.125 & 4.142 \\
\hline
\end{tabular}

Note: "J.U." means "Jump Up", "J.D." means "Jump Down"

heaters. In Fig. 3, the results show that the half-hourly variations of all household demand are distributed according to normal distributions, with same mean values but with different standard deviations. In Table 2, the statistic results of 25 customers are provided.

\subsection{Temperature}

Half-hourly average temperature of different seasons is shown in Fig. 4. From the result above, we can find that temperature changes across one day, normally with a high period of temperature in the early afternoon followed by a drop until the early morning. The peak temperature occurs at approximately $13: 00-15: 00$ in the afternoon, which is different as the peak demand at 07:00-09:00 and 18:00-21:00. Moreover, there are significant variations in average temperature between four seasons, with higher temperature expected in summer compared to in spring, autumn, and winter. In addition, the duration of high 


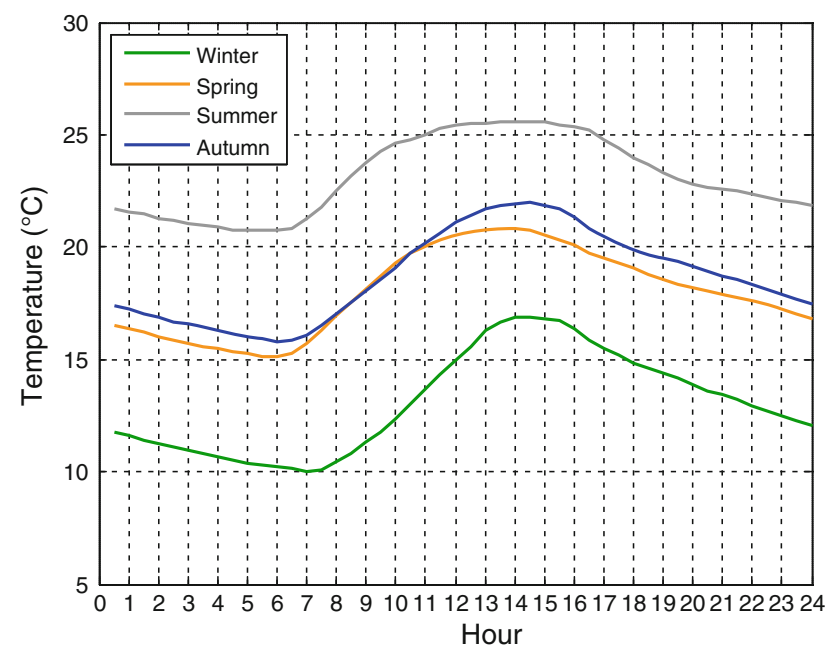

Fig. 4 Half-hourly average temperature of different seasons

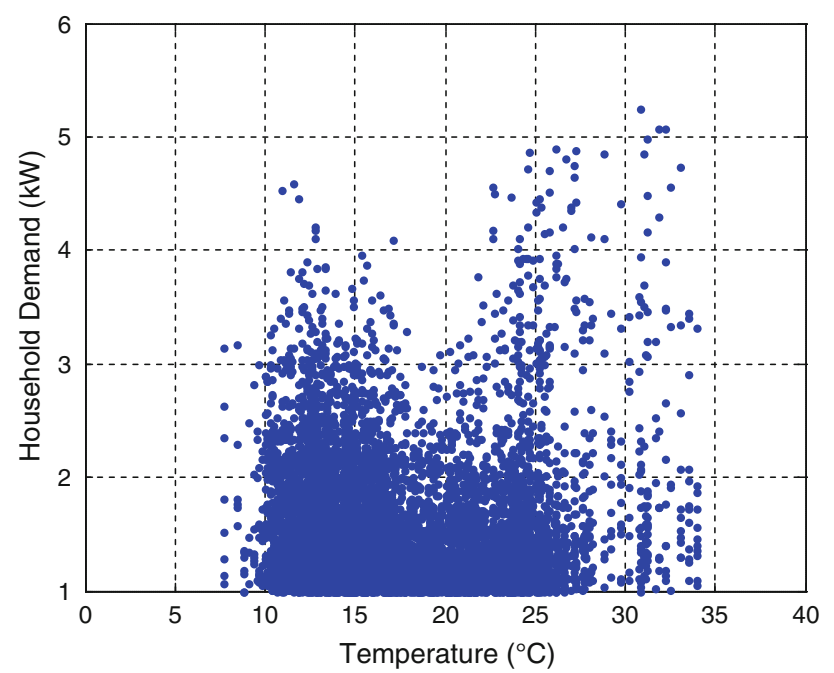

Fig. 5 Temperature vs. load of one customer

temperature periods change between four seasons, with peaks in spring and summer lasting longer.

\subsection{Temperature vs. demand}

The average household demand vs. average temperature is shown in Fig. 5. Each point represents an observation of temperature versus demand in that time period for a given working day. The striking feature of the graph is the nearly $\mathrm{v}$-shaped structure. The joint of the " $\mathrm{v}$ " in peak periods is around $18-20{ }^{\circ} \mathrm{C}$. As temperatures increase above this level, demand increases; similarly, at temperatures below this level, loads also increase. Therefore, outdoor weather conditions are crucial in determining residential energy consumption for household air-conditioning appliances.

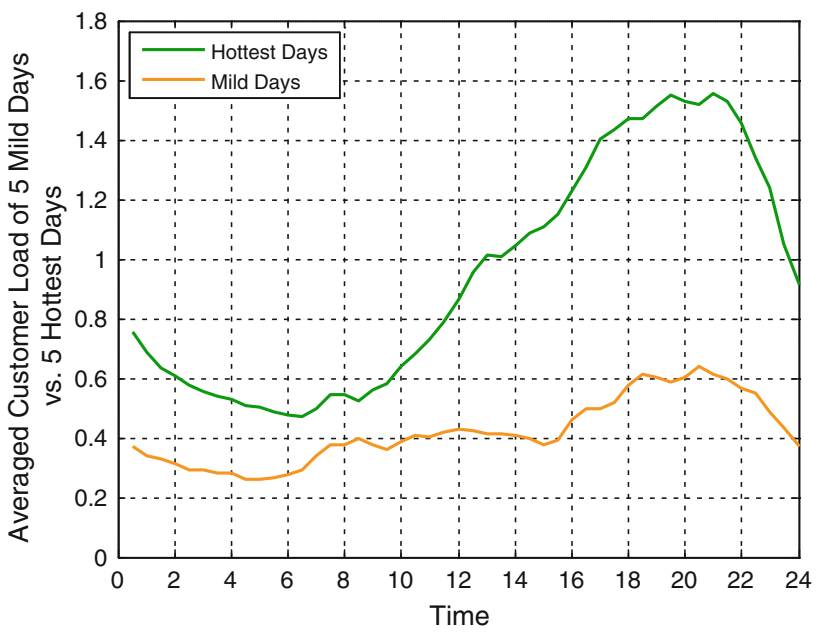

Fig. 6 Averaged customer load of five mild days vs. five hottest days

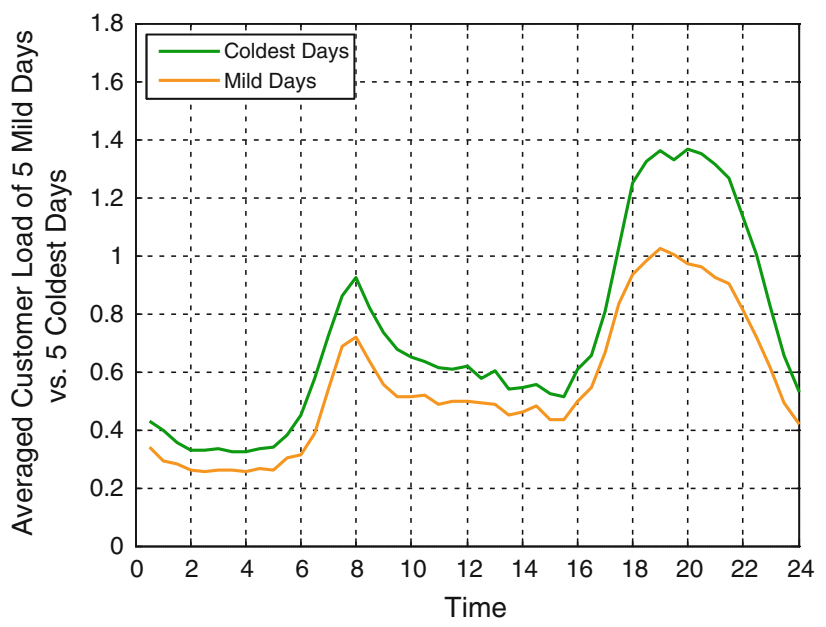

Fig. 7 Averaged customer load of five mild days vs. five coldest days

In order to show the weather impacts more clearly, all the household demand from Monday to Friday is aggregated to show the difference between five mild summer days and five hottest days in Fig. 6, five mild winter days and five coldest days in Fig. 7. The average demand curves are peakier for hot and cold days due to increased air conditioning load.

\section{Air conditioner use pattern study}

In this section, half-hourly metered customer load data from Ausgrid, combined with local weather data is used to develop an expert system which can predict air-conditioners existence and identify consumption patterns. And then air-conditioning load is extracted from household load data in order to evaluate the impacts of household air conditioners. 


\subsection{Air conditioner existence prediction}

An expert system is developed to identify the existence of air conditioner from the household load data. The expert system contains a knowledge base containing accumulated experience and a set of rules, which are expressed with natural language rules "IF ... THEN ..." [8]. This expert system could be enhanced with additions to the knowledge base or to the set of rules. With the expert system, the customer load data is firstly analyzed for jump up/down that larger than $0.5 \mathrm{~kW}$ load. The followings are some expert knowledge used to predict the existence of air conditioners.

1) Larger than median value of half-hourly load in this month $[0.5-1.0 \mathrm{~kW}(+1), 1.0 \mathrm{~kW}-1.5 \mathrm{~kW}(+2)$, $>1.5 \mathrm{~kW}(+3)]$;

2) Load jump up or jump down $0.5-1.5 \mathrm{~kW}[0.5-1.0 \mathrm{~kW}$ $(+1), 1.0 \mathrm{~kW}-1.5 \mathrm{~kW}(+2),>1.5 \mathrm{~kW}(+3)]$;

3) Find some patterns which happen at the same time every day or most of the days in this month (e.g. pool pump);

4) Do not turn on or turn off air conditioners frequently, normally keep on/off for at least $1 \mathrm{~h}$ (e.g. electric water heater) and do not use for over $24 \mathrm{~h}$;

Table 3 Survey vs. prediction results

\begin{tabular}{|c|c|c|c|}
\hline \multicolumn{2}{|c|}{ Survey } & \multicolumn{2}{|c|}{ Prediction } \\
\hline "W" & "WO" & "W" & "WO" \\
\hline 108 & 72 & 103 & 77 \\
\hline \multicolumn{2}{|c|}{ Misclassified customer } & \multicolumn{2}{|l|}{13} \\
\hline \multicolumn{2}{|c|}{ Prediction accuracy } & \multicolumn{2}{|c|}{$92.78 \%$} \\
\hline
\end{tabular}

Note: "W" means "WITH", "WO" means "WITHOUT"

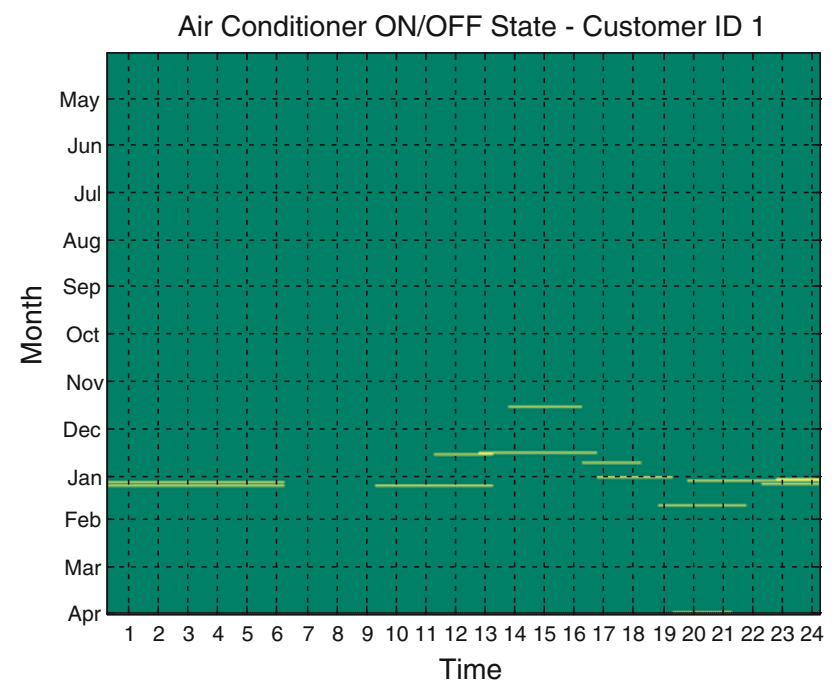

Fig. 8 Air conditioner ON/OFF states recognition of one customer
5) Normally turn on air conditioners in hot summer days or cold winter days.

Table 3 shows the survey vs. prediction results.

The promising prediction performance based on the demand data illustrates the efficiency of the proposed expert system. The recognized air conditioner ON/OFF state of one customer is provided in Fig. 8. It shows that the air conditioner is normally turned on during hot summer days. Although the power ratings of air-conditioning appliances for each house are not known, based on prediction results above, the power drawn by air conditioners at each house can be estimated.

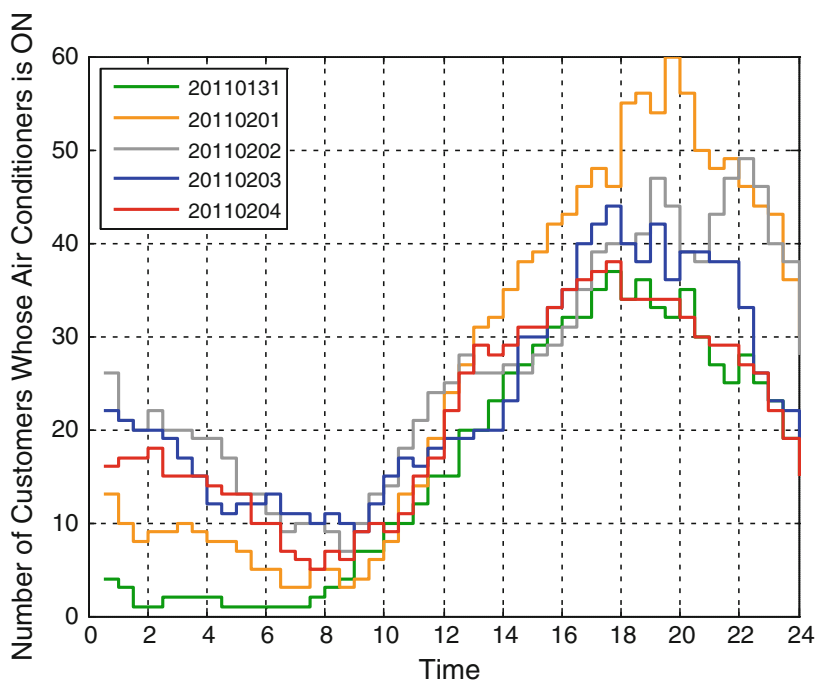

Fig. 9 Number of air conditioners is $\mathrm{ON}$ in hot summer days

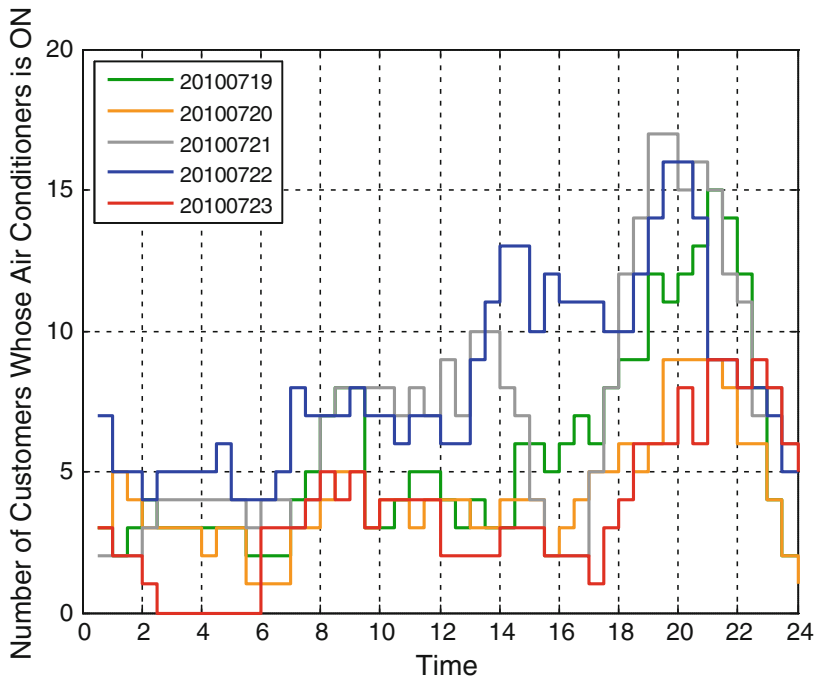

Fig. 10 Number of air conditioners is $\mathrm{ON}$ in cold winter days 
Table 4 Air conditioner on ratio in summer and winter peaks

\begin{tabular}{llcc}
\hline Season & Date & ON ratio/\% & $\begin{array}{c}\text { Average } \\
\text { time/h }\end{array}$ \\
\hline Summer & $31 / 01 / 2011$ & 62.04 & 11.67 \\
Summer & $01 / 02 / 2011$ & 83.33 & 14.02 \\
Summer & $02 / 02 / 2011$ & 75.93 & 15.44 \\
Summer & $03 / 02 / 2011$ & 73.15 & 14.20 \\
Summer & $04 / 02 / 2011$ & 65.74 & 14.30 \\
Winter & $19 / 07 / 2010$ & 2.78 & 1.00 \\
Winter & $20 / 07 / 2010$ & 2.78 & 1.00 \\
Winter & $21 / 07 / 2010$ & 1.85 & 1.00 \\
Winter & $22 / 07 / 2010$ & 6.48 & 1.00 \\
Winter & $23 / 07 / 2010$ & 2.78 & 1.00 \\
\hline
\end{tabular}

\subsection{Impacts of residential air-conditioning load}

Another factor which is of interest is how many of air conditioning units are turned on at peaks. In the studied area, the number of air conditioners turned on during hot summer days and cold winter days are presented in Figs. 9 and 10. Air conditioner on ratio in summer and winter peaks is shown in Table 4 . The study shows that more than $60 \%$ air conditioners are turned on during peak summer days, and this figure reaches $83 \%$ on extreme hot day. A lot of customers run their air conditioners over $12 \mathrm{~h}$ on peak days, but in winter, the average operation time is only $1 \mathrm{~h}$. It is reasonable because the weather at summer peak is extremely hot in Australia, so air conditioners continuously operate for longer time.

The summer heat and winter cold pushes an increase in the penetration of air-conditioning load, therefore, change both the magnitude and composition of the system demand. Along with the higher load come several problems, the extensive usage of household air-conditioner is leading to capacity straining load peaks, increasing the costs of electricity supply and volumes of greenhouse gases emissions. Moreover, if the air-conditioning load reaches certain portion of feeder load, then it is very likely to cause security and reliability problem $[9,10]$. The recent load peaks have resulted in supply disruptions, and on some occasions, high spot price on the NEM [11]. Accordingly, initiatives to curtail/shift peak demand have significant future potential value in terms of reducing growth-related infrastructure investment and improving system reliability. Fortunately, demand response programs provide an effective solution to the residential air-conditioning load problem. Demand response refers to "changes in electric usage by end-use customers from their normal consumption patterns in response to changes in the price of electricity over time, or to incentive payments designed to induce lower electricity use at times of high wholesale market prices or when system reliability is jeopardized" [12]. Turning on and off air conditioning appliances doesn't change indoor temperature immediately. As a result, air conditioning appliances become important and effective objects in demand response programs. Nowadays, increasing number of Australian utilities is moving towards supporting wide scale introduction of interval metering and design of demand response programs to improve the efficiency of the NEM. In the next section, a number of barriers blocking the further applications of demand response programs will be discussed.

\section{Barriers of demand response}

Demand response programs can effectively adjust the imbalance between supply and demand, prevent overinvestment and ensure safe and reliable operation of power network, and can promote fairer marketing by introducing new competition mechanisms [13]. However, limits on the number of customers called for demand response programs reflect the deficiency of current demand response technologies and low level of customer acceptance. Some of the major barriers are summarized as follows.

1) Lack of advanced metering infrastructure;

At current stage, a great majority of residential customers in Australia are billed for electricity using the traditional meters, which can only record the accumulated electricity consumption. Customers are billed according to the difference between the previous reading and the latest one. In the future, real-time information, such as price, will be delivered to customers more effectively through smart meters. Control signals become more widely accessible through communication networks. All these technologies will facilitate the application of more intelligent and customerfriendly demand response programs, allowing customers to identify and target discretionary loads that can be curtailed or shifted [4]. A roll-out of smart meters and a shift to time-of-use pricing structures along with inhome energy displays provides the best way to reduce air-conditioning peak load.

2) Lack of interoperability and open standards.

Although the increasing number of air conditioner suppliers ensures that their products are compatible with different demand response programs, there is no open standard for all brands of air-conditioning appliances. Furthermore, a lot of installed air-conditioning units cannot be enhanced to provide demand response function. Some elements are needed to be incorporated into these air conditioners specifically to facilitate participation in different demand response programs. 
To some extent, it may raise the overall implementation cost and reduce the potential benefits of these programs correspondingly. Governments and policy makers should encourage demand response programs with generous subsidies and with regulatory support, which will help to reduce the costs and risks to programs sponsors and to air-conditioning unit users. Furthermore, programs sponsors will be more willing to develop and offer air conditioner demand response program and end-users will have more options.

3) Lack of effective demand response programs.

A series of demand response strategies involving air conditioning systems are provided in [13]. Generally speaking, each strategy has its own merits and drawbacks. Many attempts try to merge some of the individual implementations together into a new strategy, so that it can overcome individual disadvantages and benefit from each others' advantages. The simplest but most useful strategy is to increase the temperature setting point for an entire facility, thereby reducing the electric load. It can be implemented by changing set points in one step or several steps, or by increasing over time. In the future, one or multiple strategies can be selected and applied together or in sequence to realize demand response according to specific characters of airconditioning appliances.

4) Lack of customer awareness and participation.

Creating customer awareness and increasing active participation is the most significant factors in demand response programs. A lack of understanding of initiatives has negative effects on customer awareness and participation in demand response programs. This situation is likely to change if participations are driven by consumer demand due to increased awareness, and if programs are supported by governments and utilities. For example, time-of-use pricing is necessary to motivate consumers to act on their own but is not the only way to motivate consumers to participate in demand response programs [14]. In order to recruit customers to participate in these programs, it is necessary to offer certain financial benefit. Utilities could offer a flat or graduated incentive in return for the authority to consumer's appliances up to certain number of hours each year.

\section{Conclusion}

Due to the rapid growth in residential air-conditioning unit, the development of demand response programs to directly address the air-conditioning peak load effects is becoming increasingly urgent. In this paper, the residential load data from Ausgrid combined with local weather data is used to develop an expert system, which can predict airconditioner existence and identify usage patterns. The promising prediction performance illustrates that this expert system can be used as an accessorial tool by demand response sponsors. Due to many barriers, the current development of demand management measures targeting air conditioners is relatively slow. Governments and policy makers should work together to encourage demand response programs with generous subsidies and with regulatory support. In the near future, the widespread demand response programs will play a critical role in shifting airconditioning peak load.

Acknowledgement The authors would like to thank Mr Eric Pozorski from Ausgrid for his valuable inputs to this work. This work was supported in part by an ARC Grant LP110200957.

Open Access This article is distributed under the terms of the Creative Commons Attribution License which permits any use, distribution, and reproduction in any medium, provided the original author(s) and the source are credited.

\section{References}

[1] The federal government energy white paper. Australian Government, Department of Resources, Energy and Tourism, Canberra, Canberra, Australia, 2012

[2] Demand management and planning program. Final report. TransGrid, Sydney, Australia, 2008

[3] Analysis of initiatives to lower peak demand. Final report. Energy Supply Association of Australia, Canberra, Australia, 2012

[4] Goldman C, Reid M, Levy R et al (2010) Coordination of energy efficiency and demand response. LBNL-3044E. Ernest Orlando Lawrence Berkeley National Laboratory, Berkeley, CA, USA

[5] A national demand management strategy for small airconditioners: The role of the national appliance and equipment energy efficiency program (NAEEEP). National Appliance and Equipment Energy Efficiency Committee and the Australian Greenhouse Office, Canberra, Australia, 2004

[6] Meng K, Dong ZY, Wong KP (2009) Self-adaptive RBF neural network for short-term electricity price forecasting. IET Gener Transm Dis 3(4):325-335

[7] Chen X, Dong ZY, Meng K et al (2012) Electricity price forecast with extreme learning machine and bootstrapping. IEEE Trans Power Syst 27(4):2055-2062

[8] Wong KP (1989) Expert system for protection current transformer design specification preparation. IEE Proc Gener Transm Dis 136(6):391-400

[9] Demand response spinning reserve demonstration. LBNL62761. Ernest Orlando Lawrence Berkeley National Laboratory, Berkeley, CA, USA, 2007

[10] Demand response spinning reserve demonstration-Phase 2 findings from the summer of 2008. LBNL-2490E, Ernest Orlando Lawrence Berkeley National Laboratory, Berkeley, CA, USA, 2009 
[11] Australian Energy Market Operator (AEMO). http://www.aemo. com.au. Accessed 18 Jun 2012

[12] Benefits of demand response in electricity markets and recommendations for achieving them. US Department of Energy, Washington, DC, USA, 2006

[13] Han J, Piette MA (2008) Solutions for summer electric power shortages: Demand response and its applications in air conditioning and refrigerating systems. Refrig Air Cond Electr Power Mach 29(1):1-4 (in Chinese)

[14] Power of choice - giving consumers options in the way they use electricity. Directions Paper. Australian Energy Market Commission, Sydney, Australia, 2012

\section{Author Biographies}

Robert SMITH is a senior engineer with Ausgrid, Sydney, Australia. His research interest includes energy management and grid applications.

Ke MENG (M'10) obtained Ph.D. from the University of Queensland, Australia in 2009. He is currently with the Centre for Intelligent
Electricity Networks (CIEN), The University of Newcastle, Australia. His research interest includes pattern recognition, power system stability analysis, wind power, and energy storage.

Zhaoyang DONG (M'99-SM'06) obtained his Ph.D. degree from the University of Sydney, Australia in 1999. He is now a Professor and Head of School of Electrical and Information Engineering, The University of Sydney. He is previously Ausgrid Chair and Director of the Centre for Intelligent Electricity Networks (CIEN), the University of Newcastle, Australia. His research interest includes smart grid, power system planning, power system security, load modeling, renewable energy systems, electricity market, and computational intelligence and its application in power engineering. He is an editor of IEEE Transactions on Smart Grid, and IEEE Power Engineering Letters.

Robert SIMPSON is a manager with Ausgrid, Sydney, Australia. His research interest includes energy management and grid applications. 